\title{
ERRATUM
}

\section{Erratum to: The Dexamethasone Drug Delivery System: Indications and Evidence}

Nikolas J. S. London • Allen Chiang • Julia A. Haller

To view enhanced content go to www.advancesintherapy.com

Received: May 17, 2013 / Published online: June 12, 2013

(C) Springer Healthcare 2013

Erratum to: Adv Ther (2011) 28(5):351-366

DOI 10.1007/s12325-011-0019-z

Two errors were reported in the above article. A superscript was missing in Table 1 in the first column entry on page 357 which incompletely suggested that a NNT of 11.1 was based on the ITT population, when it should have indicated the ITT subpopulation with an early and/or on time day 180 visit. Subsequently, the main text page 358 should have qualified the NNT of 11.1 by stating this result pertained to the ITT subpopulation with an early and/or on time day 180 visit. Also, the response rate attributed to the Dex DDS sham arm which is $12 \%$ in the last column of Table 1, page 356, should be $17 \%$, with a superscript specifying the early and/or on time 180 day visit cohort.

The online version of the original article can be found under doi:10.1007/s12325-011-0019-z.

N. J. S. London · A. Chiang · J. A. Haller

Retina Service, Wills Eye Institute, Thomas Jefferson

University, Philadelphia, PA 19107, USA

J. A. Haller ( $\square)$

Wills Eye Institute, 840 Walnut Street, Suite 1510,

Philadelphia, PA, USA

e-mail: jhaller@willseye.org 